\title{
RANCANG BANGUN ALAT PERAGA TUMBUKAN BERBASIS MIKROKONTROLLER UNTUK SMA
}

\author{
Widyaningrum Indrasari ${ }^{1, a)}$, Agus Setyo Budi ${ }^{1, b)}$, Dias Prima Fadilla ${ }^{2, c)}$ \\ ${ }^{\text {I}}$ Program Studi Fisika, Fakultas Matematika dan Ilmu Pengetahuan Alam, Universitas Negeri Jakarta, Jakarta \\ 13220, Indonesia \\ ${ }_{2}^{2}$ Program Studi Pendidikan Fisika, Fakultas Matematika dan Ilmu Pengetahuan Alam, \\ Universitas Negeri Jakarta, Jakarta 13220, Indonesia
}

Email: ${ }^{a)}$ widyaningrum-indrasari@unj.ac.id, ${ }^{b}$ agussb@unj.ac.id, ${ }^{c)}$ diaspfadilla@gmail.com

\begin{abstract}
Abstrak
Makalah ini memaparkan rancang bangun alat peraga tumbukan berbasis mikrokontroller di Sekolah Menengah Atas (SMA). Langkah pengembangan yang dilakukan meliputi: 1) perancangan perangkat keras, 2) perancangan perangkat lunak, dan 3) uji coba alat peraga. Alat peraga yang sudah dirancang telah divalidasi oleh ahli materi fisika dan ahli media pembelajaran fisika. Perancangan perangkat keras terdiri dari Personal Computer (PC)/Laptop, Arduino Mega 2560, Kabel USB Micro, LED Infra merah, Foto diode, Tabung akrilik $100 \mathrm{~cm}$, holder sensor, tiang penyangga bola dan bidang pantul/alas. Perancangan perangkat lunak menggunakan bahasa pemrograman $\mathrm{C}++$, dengan sistem operasi Windows, Arduino IDE 1.8.12, USB Driver dan Microsoft Excel. Sementara uji coba alat peraga dilakukan dengan cara menjatuhkan berbagai jenis bola ke lantai, dimana hambatan udara dan gesekan lintasan diabaikan. Hasil uji coba yang didapat adalah sebagai berikut: bola golf dengan lantai keramik memiliki koefisien restitusi sebesar 0,901 dengan kesalahan relatif $1,552 \%$, bola pingpong dengan lantai keramik memiliki koefisien restitusi sebesar 0,806 dengan kesalahan relatif $1,822 \%$, dan bola tenis dengan lantai keramik memiliki koefisien restitusi sebesar 0,656 dengan kesalahan relatif 5,964\%.
\end{abstract}

Kata-kata kunci: alat peraga, tumbukan, rancang bangun, koefisien restitusi.

\begin{abstract}
This paper describes the design of microcontroller-based impact props in Senior High Schools (SMA). The development steps taken include 1) hardware design, 2) software design, and 3) testing props. The props that have been designed have been validated by physics material experts and physics learning media experts. The hardware design consists of a Personal Computer (PC) / Laptop, Arduino Mega 2560, Micro USB Cable, and Infrared LED, Photodiode, $100 \mathrm{~cm}$ acrylic tube, sensor holder, ball support pole and reflective plane/base. The software design uses the $\mathrm{C}++$ programming language, with the Windows operating system, Arduino IDE 1.8.12, USB Driver and Microsoft Excel. While testing, the props were carried out by dropping various balls on the floor, where air resistance and track friction were ignored. The test results obtained are as follows: a golf ball with a tiled floor has a restitution coefficient of 0.901 with a relative error of $1.552 \%$, a ping pong ball with a tiled floor has a restitution coefficient of 0.806 with a relative error of $1.822 \%$, and a tennis ball with a tiled floor has a restitution coefficient of 0.656 with a relative error of $5.964 \%$.
\end{abstract}

Keywords: props, collision, design, restitution coefficient. 


\section{PENDAHULUAN}

Metode demonstasi menggunakan media pembelajaran di kelas terbukti dapat menunjang prinsip pembelajaran yang efektif dan dapat meningkatkan aktivitas peserta didik dalam pembelajaran [1]. Dalam hal ini untuk menunjang metode demonstrasi agar pembelajaran fisika menjadi efektif, guru dapat memanfaatkan media pembelajaran yang kontekstual. Salah satu media kontekstual yang membuat peserta didik tertarik terhadap fisika adalah dengan penggunaan alat peraga [2]. Penggunaan alat peraga yang sesuai dengan materi dalam pembelajaran sangat dianjurkan, karena peserta didik dapat menyerap materi pembelajaran secara optimal, mendalam, dan utuh. Selain mendengarkan penjelasan materi, peserta didik juga dapat terlibat langsung melalui kegiatan melihat, menyentuh, dan mengalaminya sendiri. Guru pun dapat lebih kreatif dan mencegah verbalisme dalam menyampaikan materi jika menggunakan alat peraga sehingga pembelajaran fisika akan menjadi lebih efektif $[1,3]$.

Adapun salah satu materi fisika yang kontekstual adalah fenomena tumbukan. Peristiwa tumbukan terjadi dalam waktu singkat sehingga diperlukan perangkat yang mampu menganalisis peristiwa tersebut dengan ketelitian tinggi. Pada percobaan penentuan koefisien restitusi, umumnya pengamatan parameter gerak masih dilakukan secara manual. Pengamatan dilakukan dengan peralatan sederhana seperti bola dan mistar atau meteran sebagai alat ukurnya. Posisi tinggi pantulan mengandalkan kecermatan pengamat yang kemudian diukur menggunakan mistar. Proses tersebut sangat rentan akan kesalahan baik berupa ketelitian alat ukur maupun subjektivitas pengamat terutama jika data yang dikumpulkan lebih dari satu pantulan [4]. Menurut Duden Saepuzaman (2018) percobaan penentuan koefisien restitusi yang dilakukan dengan cara manual menghasilkan nilai tidak konstan [5]. Salah satu cara meminimalisir kesalahan tersebut ialah dengan menggunakan analisis video Tracker [4, 6]. Namun, hasil penelitian tersebut masih memiliki kelemahan yaitu diperlukannya kamera dengan resolusi tinggi dan framerate per second yang memadai $[7,8]$. Pada beberapa data percobaannya pun memperlihatkan bahwa frame tidak mampu menangkap posisi benda ketika mencapai ketinggian maksimum maupun saat benda tepat menumbuk lantai [4].

Pemanfaatan teknologi lain yang dapat menggantikan peran pengamat adalah melalui sensor dan sistem kendali elektronik berbasis Arduino. Arduino adalah platform prototyping open-source hardware yang dapat digunakan untuk membuat projek berbasis pemrograman [9]. Arduino telah banyak digunakan dalam media pembelajaran fisika, manfaatnya: percobaan fisika yang awalnya dilakukan dengan metode konvensional kini dapat dilakukan dengan mudah, praktis, dan otomatis. Berdasarkan latar belakang tersebut maka dikembangkan alat peraga fisika materi tumbukan menggunakan sensor foto dioda dan sensor infra merah, dan mikrokontroler sebagai pengendali.

\section{METODOLOGI}

Pengembangan media bahan ajar seperti e-modul [10], aplikasi android [11], blended learning [12], dan eksperimen [13] menggunakan model pembelajaran 4D Thiagarajan dan ADDIE. Tetapi pada penelitian ini langkah pengembangan yang dilakukan ini diadaptasi dari Boimau (2020) [14]. Tahapan tersebut terdiri dari tiga langkah yaitu: 1) perancangan perangkat keras, 2) perancangan perangkat lunak, dan 3) uji coba alat peraga. Komponen penyusun perancangan perangkat keras dan lunak disajikan pada Tabel 1. Diagram blok sistem pada GAMBAR 1 dan rancangan desain pengembangan alat peraga ditunjukkan pada GAMBAR 2.

Pada GAMBAR 1, fungsi dari tiap-tiap blok adalah sebagai berikut: (1) Sensor infra merah berfungsi memancarkan cahaya infra merah yang tidak kasat mata sebagai kondisi logika satu kepada sensor penerima (foto dioda). (2) Sensor foto dioda berfungsi untuk mengetahui apakah cahaya infra merah terhalang benda atau tidak dengan kata lain sebagai pendeteksi cahaya. (3) Mikrokontroler (Arduino) adalah pusat kendali pada alat ini. Arduino akan mengubah input dari sensor kemudian mengolahnya dan akan menghasilkan nilai ketinggian dan waktu. (4) Microsoft Excel sebagai software pengolah data untuk tempat penyimpanan dan pengolahan data [10]. 
TABEL 1. Komponen penyusun dan perangkat pendukung

\begin{tabular}{lll}
\hline Komponen & Hardware & Software \\
\hline Mikrokontroler & Laptop $\quad$ Minimal Prosesor Dua Core dan & Windows \\
Arduino & \multicolumn{1}{c}{ RAM 2 GB } & \\
& Arduino Mega 2560 & Arduino IDE 1.8.12 \\
& Kabel USB Micro & USB Driver \\
Sensor Infra Merah & LED Infra merah & - \\
Penerima sensor Infra Merah & Foto diode & - \\
Lintasan & Tabung akrilik 100 cm, & - \\
& holder sensor, tiang penyangga & \\
Objek & Bola dan bidang pantul/alas & Microsoft Excel \\
Output data dan grafik & Personal Computer $(\mathrm{PC}) /$ Laptop & \\
\hline
\end{tabular}

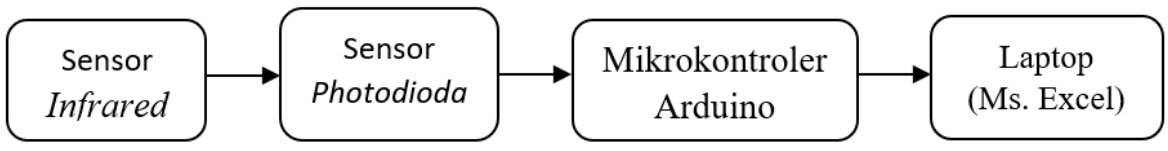

GAMBAR 1. Diagram blok sistem

Alat peraga yang dikembangkan tersusun atas sensor foto dioda receiver (RX) dan infra merah transmitter (TX) $940 \mathrm{~nm}$, ukuran 5mm, 99 pasang. Sensor foto dioda dan infra merah berperan sebagai pendeteksi gerak bola yang dipasangkan pada sisi lintasan tabung setinggi $100 \mathrm{~cm}$. Sebagai pengendali utama digunakan mikrokontroler jenis Arduino Mega 2560. Pada pengambilan data, divariasikan jenis bola sehingga dapat terlihat perbandingan fenomena lenting pada tumbukan.

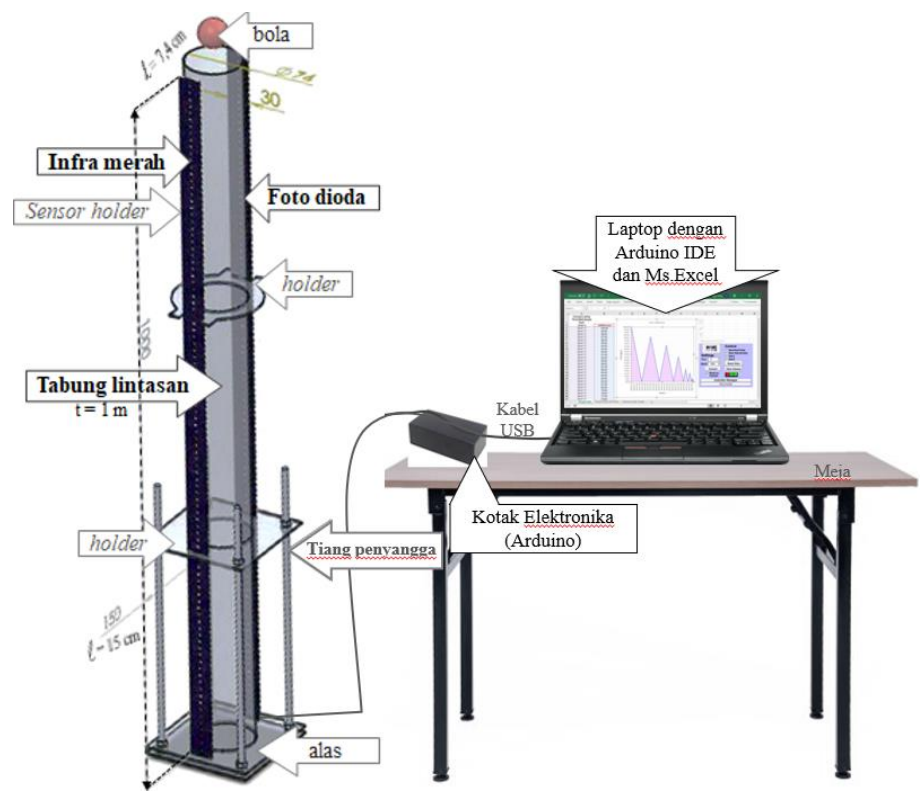

GAMBAR 2. Desain alat peraga yang dikembangkan

\section{HASIL DAN PEMBAHASAN}

Rancang bangun alat peraga pada materi tumbukan ini dibuat dengan mempertimbangkan kompetensi dasar (KD) 3.10 dan 4.10 kurikulum 2013 revisi, sehingga peserta didik dapat menyajikan hasil pengujian penerapan hukum kekekalan momentum, misalnya bola jatuh bebas ke lantai. Pada penelitian ini alat peraga yang dikembangkan terlihat pada GAMBAR 3, dan GAMBAR 4. 


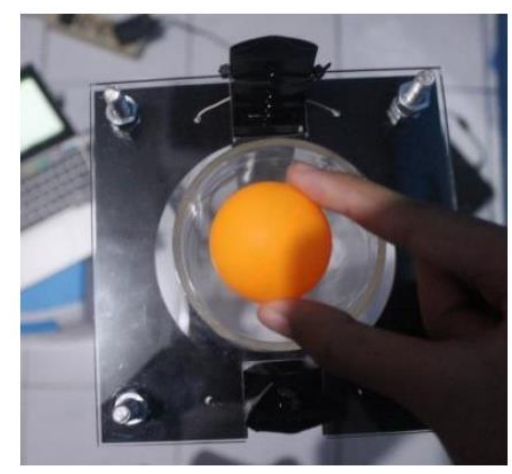

GAMBAR 1. Posisi benda sebelum dijatuhkan dalam tabung lintasan

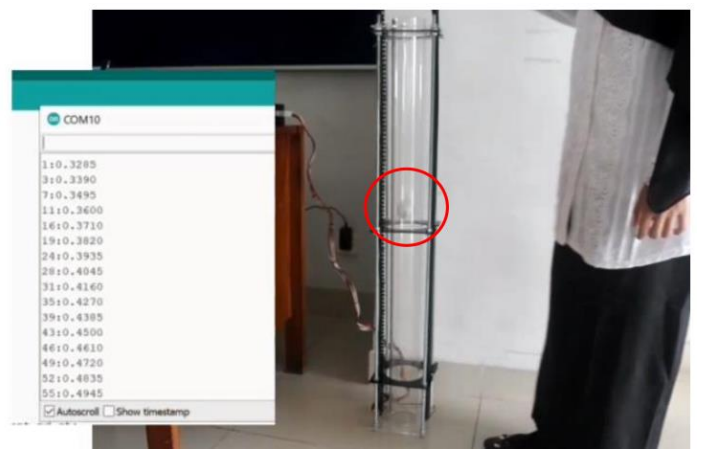

GAMBAR 2. Gerak bola dan data realtime pada monitor serial Arduino yang dihasilkan dalam suatu percobaan

Hasil utama dari rancang bangun ini adalah sebuah alat peraga fisika yang memanfaatkan sensor dalam mengukur waktu gerak pantulan bola secara otomatis, memvariasikan jenis bola dan menyelidiki pengaruh jenis bola terhadap ketinggian maksimal pantulan bola. Dalam penelitian digunakan tiga buah jenis bola yang berbeda yaitu bola golf, pingpong, dan tenis.

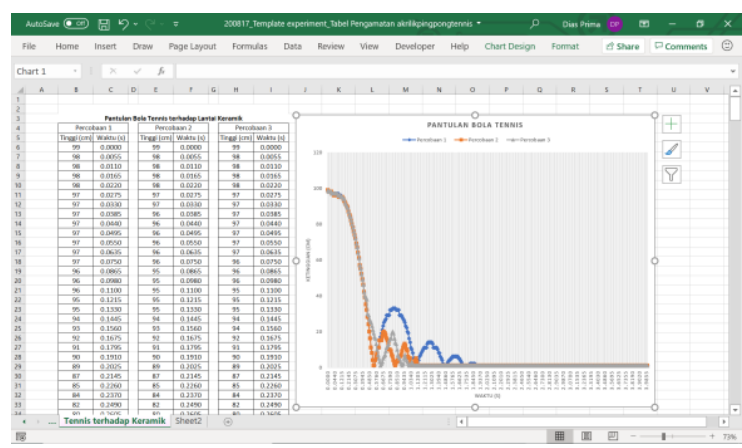

GAMBAR 5. Tampilan grafik pantulan bola tenis terhadap bidang pantul lantai keramik

Karakteristik alat peraga yang dihasilkan dapat menentukan parameter waktu dan ketinggian pantulan bola dengan akurat kemudian diintepretasikan dengan grafik melalui microsoft excel pada perangkat laptop, seperti yang ditunjukkan pada GAMBAR 5. Pantulan bola yang terjadi menunjukkan tinggi pantulan setelah tumbukan lebih rendah dibandingkan tinggi pantulan sebelum tumbukan. Data hasil percobaan tersebut dapat digunakan untuk menentukan koefisien restitusi antara bola dengan bidang pantul, seperti pada TABEL 2 .

TABEL 2. Ringkasan Data Pengujian Produk

\begin{tabular}{crc}
\hline Jenis Bola & Koefisien Restitusi & Kesalahan Relatif (\%) \\
\hline Golf & $(0,901 \pm 0,014)$ & 1,552 \\
Pingpong & $(0,806 \pm 0,015)$ & 1,822 \\
Tenis & $(0,656 \pm 0,039)$ & 5,954 \\
\hline
\end{tabular}


Terdapat perbedaan nilai koefiseien restitusi bola pingpong dan tenis jika menggunakan video tracker [15]. Hasil yang didapatkan pada penelitian Juita (2020) memiliki nilai koefisien restitusi bola tenis terhadap lantai keramik sebesar 0,787 dan untuk bola pingpong diperoleh nilai 0,795 [15]. Walaupun demikian kedua nilai tersebut memiliki kesamaan, dimana nilai koefisien restitusi bola pingpong lebih besar jika dibandingkan bola tenis. Berdasarkan data pada TABEL 2 juga dapat dilihat bahwa nilai koefisien yang dihasilkan berkisar $0<\mathrm{e}<1[16,18]$. Sehingga ketiga kasus tumbukan benda tersebut merupakan tumbukan lenting sebagian berlaku hukum kekekalam momentum dan tidak berlaku hukum kekekalan energi kinetik [19].

\section{SIMPULAN}

Rancang bangun alat peraga pada materi tumbukan berbasis mikrokontroller dapat dimanfaatkan sebagai media ajar fisika yang kontekstual. Hasil pengujian alat peraga ini menghasilkan beberapa nilai koefisien restitusi. Koefisien restitusi bola golf dengan lantai keramik sebesar 0,901 dengan kesalahan relatif $1,552 \%$, bola pingpong dengan lantai keramik sebesar 0,806 dengan kesalahan relatif $1,822 \%$, dan bola tenis dengan lantai sebesar 0,656 dengan kesalahan relatif 5,964\%.

\section{REFERENSI}

[1] T. Pramono, "Mengoptimalkan Penggunaan Alat Peraga Dalam Setiap Kegiatan Pembelajaran," Seminar Nasional PGSD Universitas PGRI Yogyakarta, ISBN 978-60250837-1-6, 2017.

[2] R. F. Muldiani, S. S. Purwaningsih, \& S. Suratmi, "Alat Peraga Pendidikan IPA Fisika dan Matematika untuk SMP Swasta Gratis Berkualitas dengan Siswa Ekonomi Lemah di Bandung Jawa Barat," Difusi, vol. 1, no. 1, pp. 32-48, 2018.

[3] D. Hamdani, K. Eva, \& S. Indra, "Pengaruh Model Pembelajaran Generatif Dengan Menggunakan Alat Peraga Terhadap Pemahaman Konsep Cahaya Kelas VIII di SMP Negeri 7 Kota Bengkulu," Jurnal Exacta, vol. 10, no. 1, pp. 79-88, 2012.

[4] R. B. Astro et al., "Penentuan Momen Inersia Katrol pada Pesawat Atwood dengan Metode Video Tracking," Seminar Nasional Inovasi Pembelajaran Sains (SNIPS), pp. 32-39, 2018.

[5] D. Saepuzaman, "Pengembangan Alat Peraga dan Lembar Kerja Percobaan Penentuan Koefisien Restitusi untuk Meningkatkan Kemampuan Siswa Bereksperimen," JPPPF: Jurnal Penelitian \& Pengembangan Pendidikan Fisika, vol. 3, no. 2, 2017, https://doi.org/10.21009/1.03204

[6] J. Persson, "Measure the coefficient of restitution for sports balls," Physics Education, vol. 47, no. 6, pp. 662-663, 2018, https://doi.org/10.1088/0031-9120/47/6/F05

[7] Fatkhulloh, "Penentuan Koefisien Restitusi menggunakan Video Based Laboratory dan Logger Pro 3," Prosiding Seminar Nasional Penelitian, Pendidikan, Dan Penerapan MIPA, 2012.

[8] F. I. Dewi, N. A. Wibowo, D. N. Sudjito, and F. Rondonuwu, "The Design of OneDimensional Motion and Two-Dimensional Motion Learning Media Using Digital Camera and Tracker-Based Air Track", JPPPF (Jurnal Penelitian dan Pengembangan Pendidikan Fisika), vol. 6, no. 1, pp. 65 - 74, Jun. 2020.

[9] Junaidi \& P. Yuliyan Dwi, "Project Sistem Kendali Elektronik Berbasis Arduino," AURA, 2018.

[10] F. Bakri, B. Z. Siahaan, and A. H. Permana, "Rancangan Website Pembelajaran Terintegrasi dengan Modul Digital Fisika Menggunakan 3D PageFlip Professional", JPPPF (Jurnal Penelitian dan Pengembangan Pendidikan Fisika), vol. 2, no. 2, pp. 113 - 118, Dec. 2016. 
[11] D. Ambarwulan and D. Muliyati, "The Design of Augmented Reality Application as Learning Media Marker-Based for Android Smartphone", JPPPF (Jurnal Penelitian dan Pengembangan Pendidikan Fisika), vol. 2, no. 1, pp. 73 - 80, Jun. 2016.

[12] Y. R. Denny, I. S. Utami, S. Rohanah, and D. Muliyati, "The Development of Blended Learning Model using Edmodo to Train Student Critical Thinking Skills on ImpulseMomentum Topic", JPPPF (Jurnal Penelitian dan Pengembangan Pendidikan Fisika), vol. 6, no. 1, pp. 113 - 120, Jun. 2020.

[13] Y. R. Liana, S. Linuwih, and S. Sulhadi, "The Development of Thermodynamics Law Experiment Media Based on IoT: Laboratory Activities Through Science Problem Solving for Gifted Young Scientists", JPPPF (Jurnal Penelitian dan Pengembangan Pendidikan Fisika), vol. 6, no. 1, pp. 51 - 64, Jun. 2020.

[14] I. Boimau, R. N. K. Mellu, \& M. R. Manuain, "Rancang Bangun Alat Praktikum Viskometer Berbasis Android," Wahana Fisika, vol. 5, no. 1, 2020.

[15] A. Nuryaman, E. Mulyana, \& R. Mardiati, "Rancang Bangun Prototipe Alat Pengukur Kecepatan Kendaraan Dengan Sensor Infra Merah," SENTER: Seminar Nasional Teknik Elektro, 2017.

[16] S. T. Juita dkk, "Penentuan koefisien restitusi benda menggunakan metode video tracking," OPTIKA: Jurnal Pendidikan Fisika, vol. 4, no. 1, Juni 2020.

[17] C. Douglas, “Giancoli Fisika Edisi Kelima Jilid 1,” Jakarta: Erlangga, 2001.

[18] Sears \& Zemansky, "Fisika Universitas Edisi kesepuluh Jilid 2,” Jakarta: Erlangga, 2001.

[19] M. D. Kholifudin, "Menentukan Koefisien Restitusi Tumbukan dengan Analisis Konversi Sudut Penyimpangan," Jurnal Penelitian Pembelajaran Fisika, vol. 10, no. 1, pp.64-69, 2019. 